\title{
MECHANICAL PROPERTIES OF HIGH-Mn AUSTENITIC STEEL TESTED UNDER STATIC AND DYNAMIC CONDITIONS
}

\begin{abstract}
The purpose of the paper is to investigate $\mathrm{X} 73 \mathrm{MnSiAlNbTi25-1-3} \mathrm{high} \mathrm{manganese} \mathrm{austenitic} \mathrm{steel} \mathrm{containing} 0.73 \% \mathrm{C}$ to determine structural mechanisms decisive for increasing a reserve of cold deformation energy of such steel. The influence of a strain rate on the structure of the investigated steels and on the structural mechanisms decisive for their properties was analysed. Specialist research instrumentation was used for this purpose such as Scanning Transmission Microscopy (including EBSD examinations), conventional and high-resolution transmission electron microscopy together with diffraction examinations and metallographic examinations. It was found that the principal cause of an increased reserve of cold deformation energy of the investigated steels in dynamic conditions is the activation of mechanical twinning in the mutually intersecting systems in austenite grains and annealing twins, which are densifying when a cold deformation rate is growing, thereby confirming the basic mechanism of TWIP (TWinning Induced Plasticity).

Keywords: high manganese steel, TWIP mechanism, strain rate, mechanical properties, structure
\end{abstract}

\section{Introduction}

Much higher quality requirements for automotive vehicles and other means of transport are imposed these days as compared to the situation seen just a few years ago. This concerns not only comfort and aesthetics, but mainly travel safety and operation of all automotive vehicles and means of transport in general. Unfortunately, very high global production rates of cars and vehicles and a constantly growing group of vehicles on roads are leading to a rising number of road collisions and accidents. It is therefore crucial to design structural parts of road vehicles in such a way and to apply such materials which deform or rapture as planned during a collision. It is known that, as a result of the acting strain, a material is cracking into parts, which is associated with, respectively, the initiation and propagation of cracking. Brittle cracking is characterised by a very small portion of plastic deformation and small energy absorbed before complete fracture [1-4]. Ductile cracking is however characterised by a very high portion of plastic deformation and energy absorbed before complete fracture. Ductile cracking is a property describing the ability of the material containing cracks to withstand cracking [5-7]. It is pointed out by analysing the literature data that the plastic deformation energy of engineering materials can be used to prevent their damage before their decohesion process takes place, which became a basis for studies identifying the ability of steels containing at least $25 \% \mathrm{Mn}$ with an austenitic structure with the addition of $\mathrm{Al}$ and $\mathrm{Si}$, to prevent cracking by, notably, activation of mechanical twinning during cold plastic deformation [8-11]. Steel can be additionally strengthened by adding microadditions of $\mathrm{Ti}, \mathrm{Nb}$ and $\mathrm{B}[12,13]$ to such steels, by employing thermomechanical treatment in a manufacturing process through refinement of an austenite structure.
A synergic interaction of the mentioned factors and structural effects in relation to the mentioned steels also satisfies the requirements of two EU directives. The first directive concerns steel produced on demand, in consistency with the technological foresight of Europe obtained in FutMan [14] and ManVis [15] projects, by offering engineering materials for car manufacturers with the greatest energy absorption during cold dynamic plastic deformation, e.g. during a road accident. The second directive concerns the limitation of fatalities and permanent body damages and a significant improvement in passive safety of car passengers and drivers by limiting a portion of energy consumed directly for cracking processes [16-18]. The following are the factors having an effect on cracking ductility: temperature, strain rate, dependency between strength and material ductility. The appropriately selected chemical composition of steel and the appropriately selected technological process allow to achieve a structure and a set of strength and plastic properties of steel, as illustrated by indicators equal to tensile strength multiplied by maximum elongation (the field under the curve - an integral of stress variations in the function of deformation is a measure of cracking ductility), whilst relatively high strain energy per unit volume ensures energy absorption and prevents premature fracture of the damaged car components. The intensive mechanical twinning mechanisms induced in high manganese austenitic steels, ensuring an increased reserve of energy unprecedented for other steels, allows to shapen technologically parts with a complicated shape and to unload energy during plastic deformation at high rates, in particular during a road accident [1-7,19-21]. The modern quality requirements for automotive vehicles and other means of transport relate primarily to implementation of programmes

* SILESIAN UNIVERSITY OF TECHNOLOGY, DIVISION OF MATERIALS PROCESSING TECHNOLOGY, MANAGEMENT AND COMPUTER TECHNIQUES IN MATERIALS SCIENCE, INSTITUTE OF ENGINEERING MATERIALS AND BIOMATERIALS, 18A KONARSKIEGO STR., 44-100 GLIWICE, POLAND

\# Corresponding author: wojciech.borek@polsl.pl 
improving the passive safety of traffic users, to possibly lowest weight of vehicles and to the resulting reduction in fuel consumption and in the related emission of fumes into the air, as well as to comfort, aesthetics and many other aspects. It is claimed according to the views presented at present [8-10] that new steels with an austenitic A1 structure containing Mn at a concentration of above $25 \%$ and $\mathrm{Si}$ and $\mathrm{Al}$ may ensure significant progress, especially in automotive applications [14], as opportunities have already been practically exploited to improve strength and plasticity for steel with an A2 lattice structure - ferritic and martensitic steels (HSLA type - High Strength Low Alloy steels, BH type - Bake Hardening steels, IF type - Interstitial Free, IS type - Isotropic Steels, multiphase steels of DP type - Dual Phase, TRIP type - TRansformation Induce Plasticity steels, CP type - Complex Phase, PM type Partially Martensitic steels and MS type - Martensitic Steels) [1, 4-7, 22-32]. Steels containing 22-35\% of Mn exhibit a fully stable austenite structure, and at a concentration of more than $25 \% \mathrm{Mn}$, they show plasticity induced by mechanical twinning during cold plastic deformation, called the TWIP effect. If the concentration of $\mathrm{Mn}$ is further increased, the plastic properties of steel are not further influenced [8-10], but have a favourable effect when added at the same time to $3 \%$ of $\mathrm{Al}$ and $3 \%$ of Si. A group of structural effects occurring in such steels during technological processes of hot plastic deformation and in conditions simulating road accidents with cold plastic deformation are decisive for the suitability of such steels for application in the motor industry. The above-mentioned reasons sourced from the literature formed a basis for selection of X73MnSiAlNbTi25-1-3 steel for investigations in this work.

High manganese austenitic steels can be used for plates and structural parts of cars as, respectively, reinforcement and controlled plastic deformation zones of cars (body), behaving in a controlled and pre-programmed manner, during dynamic cold plastic deformation occurring especially in a car accident, and as reinforcement of side doors enabling to absorb as much energy as possible during side car impact, which also relates to truck cabins [1,22-27]. For this reason, the work investigates the influence of a cold plastic deformation rate of X73MnSiAlNbTi25-1-3 steel in the range from $0.008 \mathrm{~s}^{-1}$ (static conditions) to deformation at a rate of $1000 \mathrm{~s}^{-1}$ (dynamic conditions), simulating one of the possible plastic deformation cases which may take place during a car accident. Other cases taking place during a car accident also include variations in temperature conditions in which a road vehicle is moving, taking into account negative and positive temperature. These aspects will be discussed in the next publications of the article's author.

\section{Materials}

The material for the research is represented by new high manganese designated steel of the Mn-Si-Al type developed experimentally. The chemical composition (Table 1) of the studied steel has been so selected as to achieve the steel with a TWIP austenitic structure, hence permitting to analyse issues associated with plastic deformation and mechanical properties of the studied steel for its application for structural parts of cars.

Due to a high concentration of $\mathrm{Mn}$ in the chemical composition of the investigated steels of approx. $25 \%$ and approx. $1 \%$ of $\mathrm{Si}$ and approx. of $3 \%$ of $\mathrm{Al}$ with a controlled concentration introduced of $\mathrm{Nb}$ and $\mathrm{Ti}$ microadditions with strong chemical affinity to $\mathrm{C}$ and $\mathrm{N}$, during prior hot plastic working in appropriately selected conditions, dispersive nitrides, carbonitrides and carbides, released on dislocations in hot plastically deformed austenite, are inhibiting the growth of recrystallized austenite grains, which makes it easier to produce a fine-crystalline structure and thus to enhance steel strength. A clearly higher concentration of $\mathrm{Al}$ than $\mathrm{Si}$ in the investigated steels is meant to eliminate an advantageous effect of this element on steel castability and on the steel surface condition in a hot forming process.

\section{Experimental}

Metallographic examinations were carried out with the test specimens mounted in thermosetting resins. A mixture of a $10 \%$ nitric acid solution in ethyl alcohol was used as an etching reagent to expose austenite grain boundaries in the structure of the investigated steels. The structural observations of the examined materials were carried out with an MEF4A light microscope by LEICA and Axio Observer by ZEISS. Metallographic examinations were also performed with a Supra 35 electron scanning microscope by ZEISS equipped with a high-resolution gun with Schottky field emission using secondary electrons (SE) detection and back scattered electrons (BSE), with the accelerating voltage of $20 \mathrm{kV}$ and magnification of 500-25000 times.

Diffraction examinations with back scattered electrons by a Supra 35 electron scanning microscope by ZEISS equipped with a camera and software for EBSD (Electron BackScatter Diffraction) technique and a Trydent XM4 adapter by EDAX were undertaken to determine a crystallographic orientation of austenite grains and to analyse quantitative aspects. The examinations were made with unetched specimens finished by a vibratory polishing technique with a VibroMet 2 device by BUEHLER for at least 4 hours. Scanning was carried out with a step of 0.05 to $0.4 \mu \mathrm{m}$, and the results obtained were processed with TSL OIM software.

Diffraction examinations and examinations of the structure of thin foils were performed with a JEM 3010 transmission electron microscope (TEM) by JEOL and a TITAN 80-300 high-resolution transmission electron microscope (HRTEM) by FEI equipped with a STEM scanning system. The accelerating voltage value during measurements was $300 \mathrm{kV}$, and the

Chemical composition of new-developed high-manganese TWIP-type steel, mass fraction

\begin{tabular}{|c|c|c|c|c|c|c|c|c|c|}
\hline \hline \multirow{2}{*}{ Steel designation } & \multicolumn{9}{|c|}{ Chemical composition, mass fraction } \\
\cline { 2 - 20 } & $\mathrm{C}$ & $\mathrm{Mn}$ & $\mathrm{Si}$ & $\mathrm{Al}$ & $\mathrm{Nb}$ & $\mathrm{Ti}$ & $\mathrm{Ce}$ & $\mathrm{La}$ & $\mathrm{Nd}$ \\
\hline X73MnSiAlNbTi25-1-3 & 0.73 & 25.50 & 1.30 & 3.20 & 0.047 & 0.027 & 0.004 & 0.002 & 0.001 \\
\hline
\end{tabular}


observations were performed in the classical mode (TEM JEM 3010 and TITAN), with a spatial resolution of below 0.10 nm (TITAN) and approx. $20 \mathrm{~nm}$ (JEM 3010), and also in the scanning mode (STEM - TITAN) with spatial resolution of up to $0.14 \mathrm{~nm}$.

The tests of mechanical properties were made with a universal tensile testing machine Z100 by ZWICK with the maximum load range of up to $100 \mathrm{kN}$, and the results obtained were analysed with testXpert II software also by ZWICK. An analogue extensometer mounted directly to a specimen with rectangular section $(2 \times 12.5 \mathrm{~mm})$ and measuring length of $50 \mathrm{~mm}$ was used to measure elongation during a static tensile test of the specimens. Some specimens were additionally stretched to the set elongation value of 5, 10, 20 and $30 \%$ to analyse twinning intensity.

Mechanical properties in dynamic conditions were examined with a rotary hammer RSO from WPM Lipsk. The rotary hammer used for the examinations of mechanical properties of the investigated steels enables to deform specimens with the impact rate of the percussion ram of 3 to $50 \mathrm{~m} / \mathrm{s}$, corresponding to a strain rate in the range of $10^{2}$ $10^{3} \mathrm{~s}^{-1}$. The investigations of dynamic properties were made at a deformation rate of 250,500 and $1000 \mathrm{~s}^{-1}$.

\section{Results and discussion}

Figures 1-4 show the structures of the investigated X73MnSiAlNbTi25-1-3 steel subjected to cold plastic deformation in a static tensile test and in dynamic conditions at a strain rate of, respectively, 250 and $500 \mathrm{~s}^{-1}$. It was found according to the outcomes of the structural examinations performed with a light microscope and a high-resolution electron transmission microscope that intersecting slip bands and mechanical twins and micro twins were viewed in austenite grains and in annealing twins (Fig. 1-3). As a cold plastic deformation rate is growing, so the density of intersecting slip bands and deformation twins is increasing (Fig. 4).

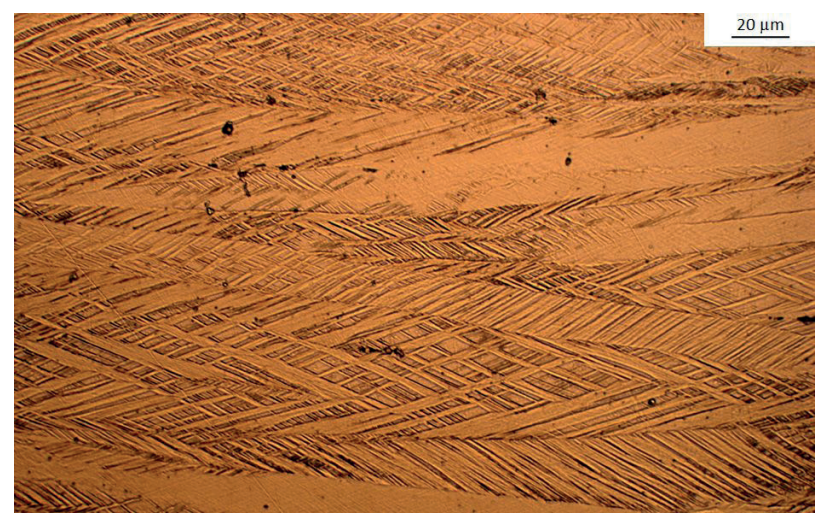

Fig. 1. Structure of high manganese austenitic X73MnSiAlNbTi25-1-3 TWIP-type steel with mechanical twins and slip bands in both systems obtained after tensile test in static conditions

It was found by examining thin foils in a transmission electron microscope that the structure of newly developed high manganese austenitic steels X73MnSiAlNbTi25-1-3 after a static tensile test consists mainly of grains elongated in the direction corresponding to the direction of the tensile force applied with a high density of dislocation with numerous twins (Fig. 2) located mainly in strongly deformed grains with intersecting various slip systems. a)

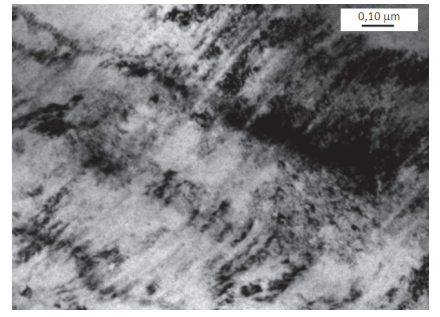

c)

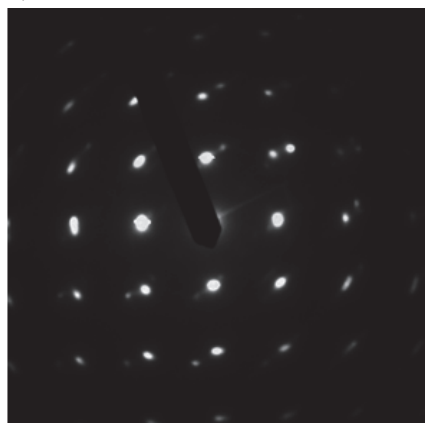

b)

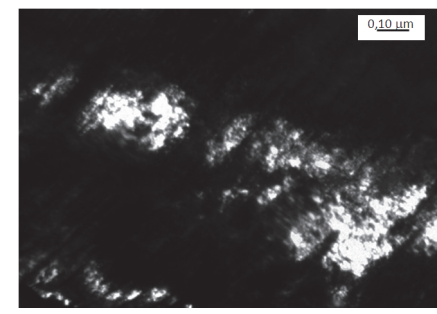

d)

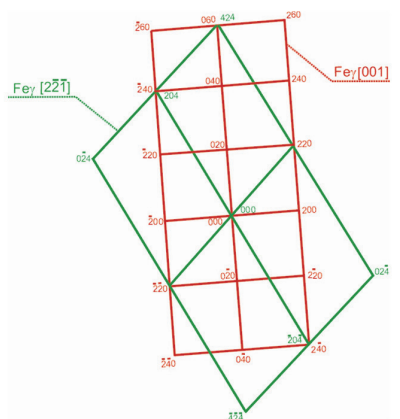

Fig. 2. Deformation twins in the X73MnSiAlNbTi25-1-3 TWIP-type steel, in state after static tensile test until elongation of 5\%: a) bright field, b) dark field from the ( $\overline{2} 0$ ) plain Feg, c) diffraction pattern, d) solution of the diffraction pattern in Fig 6c. Feg [001] is the zone axis of the matrix as well the corresponding zone axis of the twins Feg $[2 \overline{2} \overline{1}]$ a)

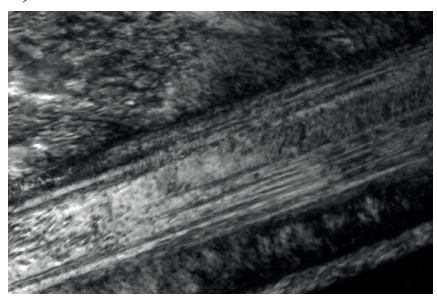

c)

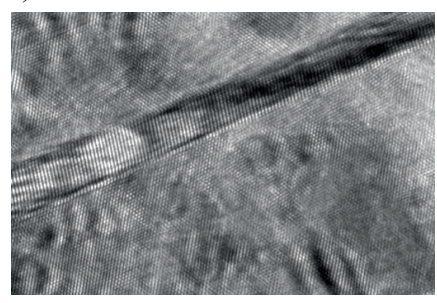

e)

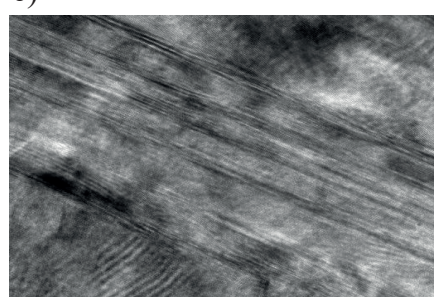

b)

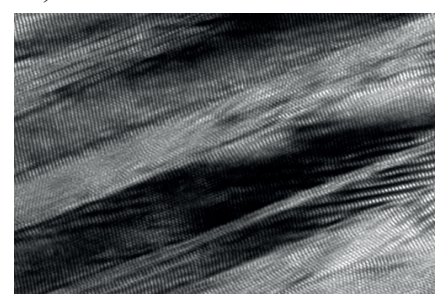

d)

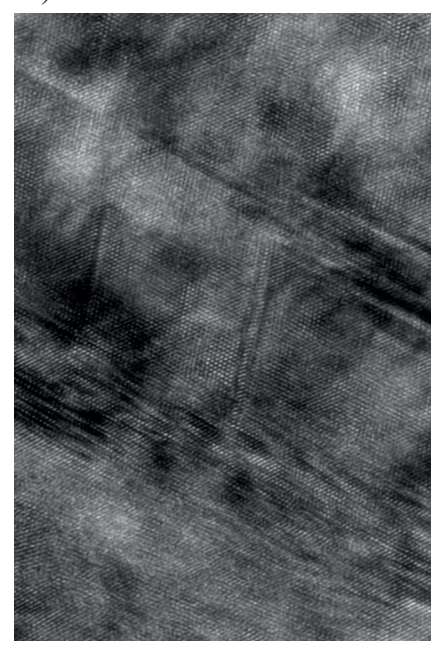

Fig. 3. Deformation twins in the structure of thin foils of X73MnSiAlNbTi25-1-3 steel in the state after static tensile test until rupture, viewed in a high-resolution electron transmission microscope a)-c) parallel systems; d)-e) systems of intersecting twins in two different systems 
The basic mechanism of TWIP closely linked to cold plastic deformation by the activation of twinning in the intersecting systems (Fig. 3) was confirmed with a highresolution electron transmission microscope. A qualitative analysis - at a nanometric scale, EBSD, in a scanning electron microscope - of the structure of X73MnSiAlNbTi25-1-3 steel stretched dynamically at room temperature $\left(20^{\circ} \mathrm{C}\right)$ at a rate of $500 \mathrm{~s}^{-1}$ (Fig. 5) confirms the presence of twins in different intersecting systems and of mutually intersecting slip bands and deformation bands, as shown in the attached crystallographic orientation maps and maps of presence of crystallographic misorientation angles between grains. The fractures of the specimens ruptured in such conditions are of ductile nature (Fig. 6).

The examinations of mechanical properties must be performed in static and dynamic conditions and examinations results have to be linked to structure changes to assess the suitability of the investigated steels for structural parts susceptible to controlled cold plastic deformation in service, especially for cars.

The investigated steel reaches the following values: yield strength of $597 \mathrm{MPa}$, ultimate tensile strength of 668 $\mathrm{MPa}$, uniform elongation of $43 \%$, and the ratio $Y S_{0.2} / \mathrm{UTS}$ reaches the value of 0.87 . The most important mechanical property characterising high manganese steels, essential for the objective of the work, is a strain energy per unit volume $E$, i.e. energy which can be accumulated in a dynamic load, e.g. in road collision of vehicles. The average strain energy per unit volume for the investigated steels was determined by calculating a field area under the actual stress-actual strain curve. Figure 7 presents a representative stress-strain curve with the determined value of strain energy per unit volume for the investigated X73MnSiAlNbTi25-1-3 steel subjected to cold deformation in static conditions. An average strain energy per unit volume value of the specimens deformed in static conditions is $280 \mathrm{MJ} / \mathrm{m}^{3}$. a)

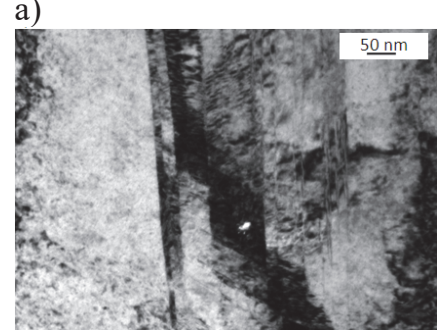

c)

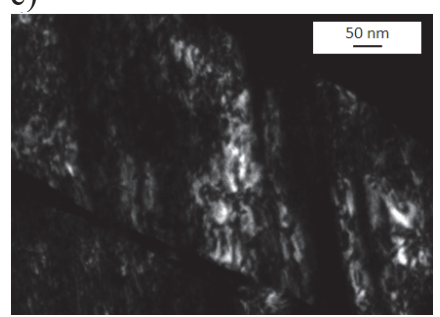

b)

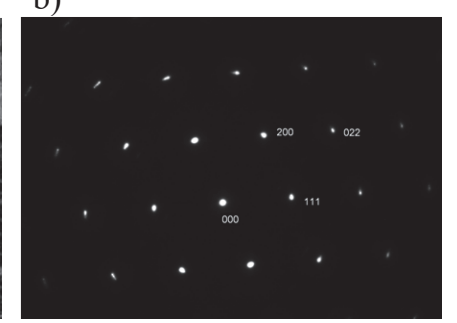

d)

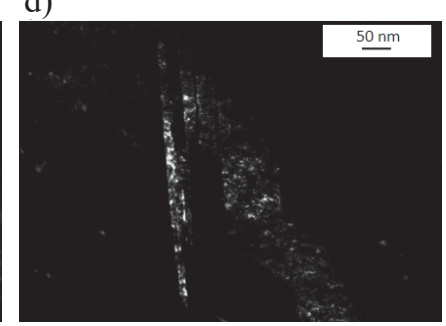

Fig. 4. Austenitic structure with deformation and micro twins in the X73MnSiAlNbTi25-1-3 TWIP-type steel, in state after dynamic tensile test: a) bright field, b) diffraction pattern from Fig. 4a, c) dark field from the (022) plain Fe $\gamma$, d) dark field from the (200) plain Fey a)

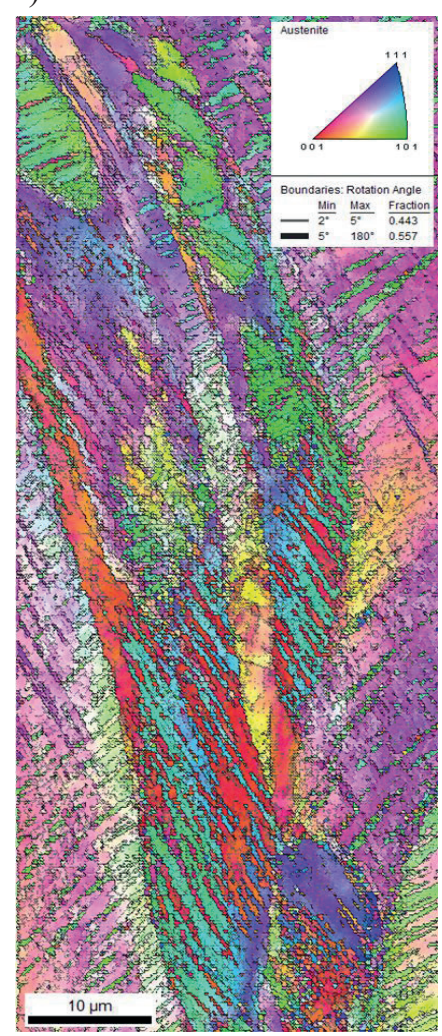

b)

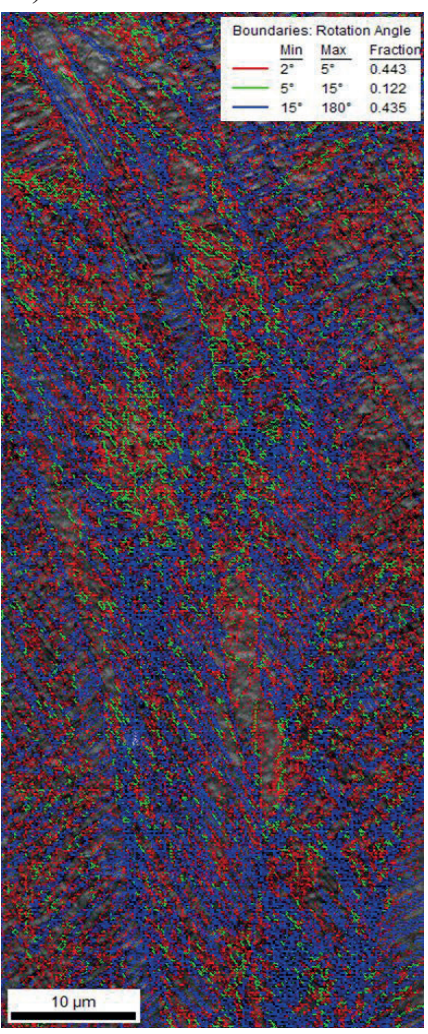

Fig. 5. Structure of X73MnSiAlNbTi25-1-3 steel deformed dynamically on a rotary hammer at room temperature $\left(20^{\circ} \mathrm{C}\right)$ at a rate of $500 \mathrm{~s}^{-1}$; a) crystallographic orientation map with misorientation angles marked in the range of $2-5^{\circ}(54 \%), 5-180^{\circ}(46 \%)$; b) map of crystallographic misorientation angles between grains, angles are marked in the range of $2-5^{\circ}(53.6 \%), 5-15^{\circ}(17.7 \%)$ and $15-180$ $(28.7 \%)$

a)

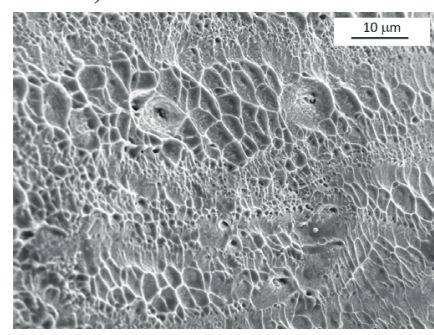

b)

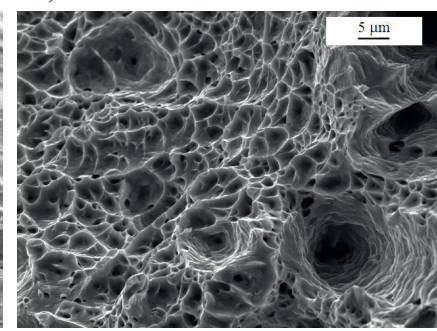

c)

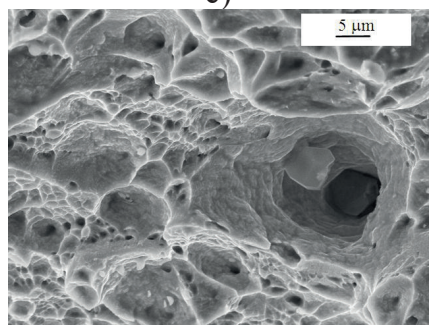

Fig. 6. Fracture structures of X73MnSiAlNbTi25-1-3 steels deformed until rupture a) in static conditions; b), c) in dynamic conditions with a strain rate of $250 \mathrm{~s}^{-1}$; structures observed in scanning electron microscope 


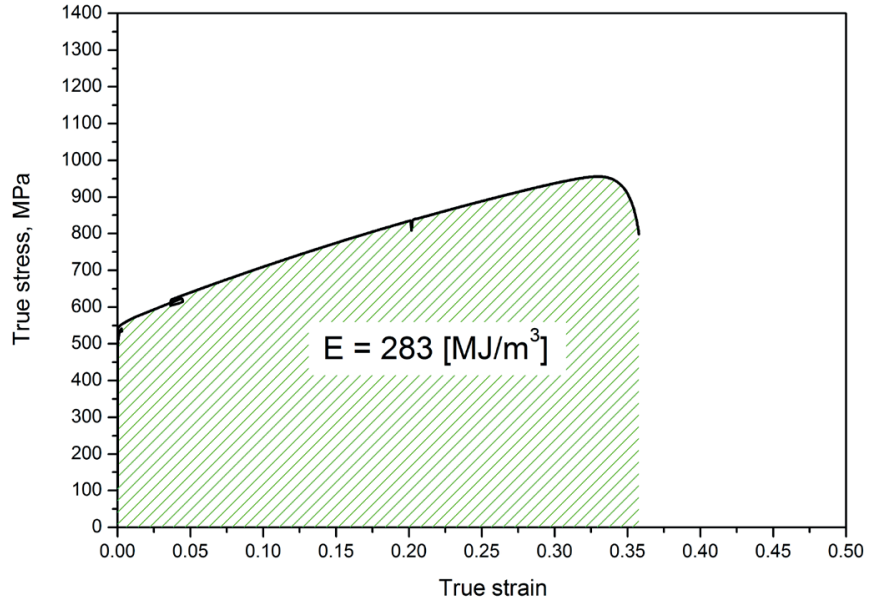

Fig. 7. Representative tensile curve of selected X73MnSiAlNbTi25-1-3 TWIP-type steel with designated strain energy per unit volume after static tensile tests in ambient temperature

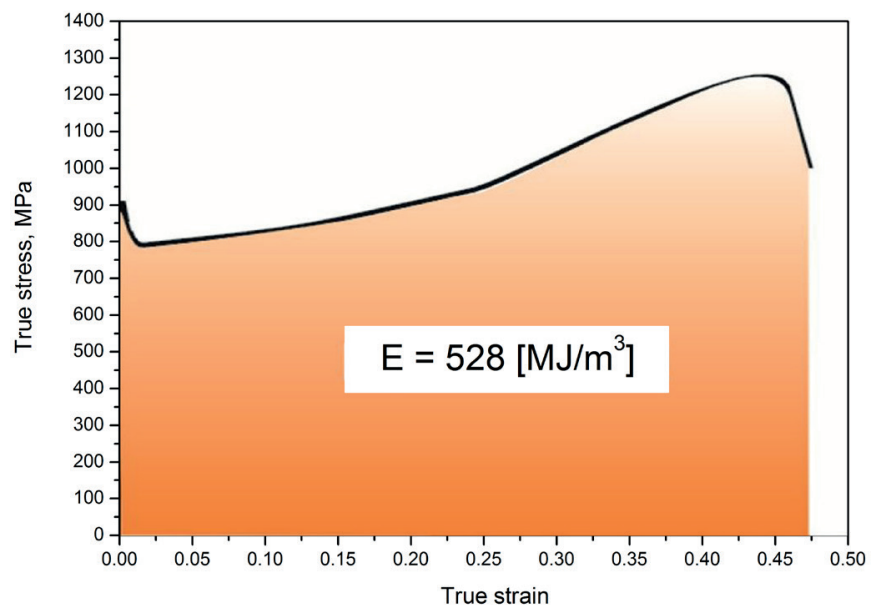

Fig. 8. Representative tensile curve of selected X73MnSiAlNbTi25-1-3 TWIP-type steel with designated strain energy per unit volume after dynamic tensile tests with strain rate $500 \mathrm{~s}^{-1}$

The most interesting results in terms of information for possible application in transport structures are offered by tensile strength tests at high rates. An increase of a plastic deformation rate at constant test temperature increases a yield strength of the investigated X73MnSiAlNbTi25-1-3 steel from 597 to $965 \mathrm{MPa}$, so the growth is by about $60 \%$ in relation to examinations in static conditions $\mathrm{YS}_{0.2}$ (Fig. 9). An increase in the rate of plastic deformation to $1000 \mathrm{~s}^{-1}$ is increasing ultimate tensile strength from approx. 690 to approx. 1100 $\mathrm{MPa}$. Uniform elongation reaches the maximum value of $50 \%$ for the investigated steel at a strain rate of $250 \mathrm{~s}^{-1}$ (Fig. 9). A further increase in a strain rate reduces the studied plasticity by about $20 \%$. As a plastic deformation rate is growing, so is growing a value of strain energy per unit volume. Figure 8 presents a stress-strain curve of the specimen deformed at a rate of $500 \mathrm{~s}^{-1}$ with a strain energy per unit volume value designated at $528 \mathrm{MJ} / \mathrm{m}^{3}$.

Further growth of a cold plastic deformation rate to 1000 s-1 leads to the further growth of strain energy per unit volume to $574 \mathrm{MJ} / \mathrm{m}^{3}$, i.e. a strain energy per unit volume value higher by $110 \%$ as compared to the strain energy per unit volume value obtained in static conditions.

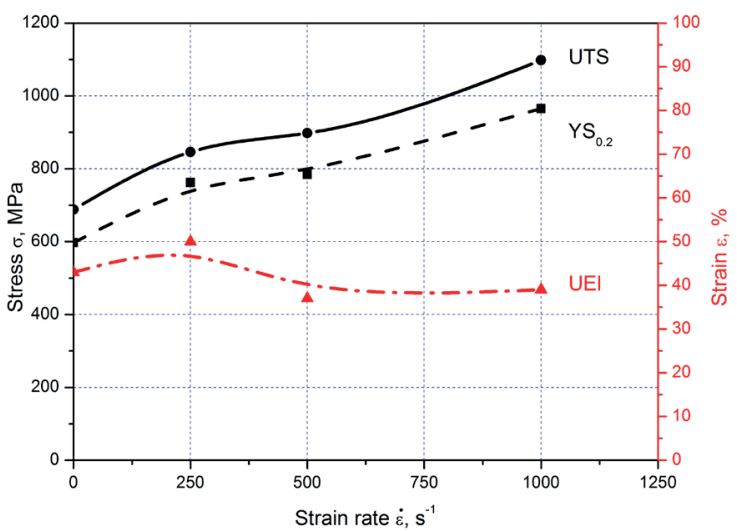

Fig. 9. Influence of strain rate on mechanical properties of high manganese X73MnSiAlNbTi25-1-3 TWIP-type steel: yield strength $\left(\mathrm{YS}_{0.2}\right)$, ultimate tensile strength (UTS) and uniform elongation (UEl)

\section{Conclusions}

It was demonstrated that strain energy per unit volume during dynamic stretching at a rate of, respectively, 250, 500 and $1000 \mathrm{~s}^{-1}$, understood as energy equal to an integral under a curve of stress variations in the function of deformation, depending on the deformation rate is, respectively 545,528 and $574 \mathrm{MJ} / \mathrm{m}^{3}$. For comparison, strain energy per unit volume at a static load is $273 \mathrm{MJ} / \mathrm{m} 3$ (Fig. 7), which is no more than $50 \%$ of the relevant values characteristic for dynamic stretching. The ultimate tensile strength of, respectively, 688, 846, 898 and $1098 \mathrm{MPa}$ for the investigated X73MnSiAlNbTi25-1-3 steel and a strain rate of $0.01,250,500$ and $1000 \mathrm{~s}^{-1}$, and also the uniform elongation of 42, 50, 36 and $38 \%$ are corresponding to such values. It was found that the primary cause of a higher reserve of cold plastic deformation energy in static conditions, and especially dynamic conditions, is the activation of mechanical twinning in the intersecting systems (Fig.1), confirmed in the structure of thin foils in a transmission (Figs. 2, 4) and high-resolution electron microscope (Fig. 3 ) and by an EBSD analysis (Fig. 5). The fractures of the specimens ruptured in such conditions are of ductile nature, as confirmed by the results of fractographic examinations in a scanning electron microscope (Fig. 6). Grains, elongated in the direction corresponding to the direction of tensile force with a high density of dislocation with numerous twins located mainly in strongly deformed grains with intersecting various slip systems, exist within the structure of the ruptured specimens. The basic mechanism of TWIP linked to cold plastic deformation by the activation of mechanical twinning in the intersecting systems and the mutual intersection of slip bands and deformation twins in austenite grains and annealing twins was thus confirmed.

The described properties of the studied steels show it is feasible and purposeful to employ them for cover (body) parts of cars and other structural parts of cars deforming intensively in dynamic conditions of external loads, which also takes place in a road accident. It is therefore possible to use plastic deformation energy of the investigated steels in such conditions to prevent rupture until their plastic deformation lasts. 


\section{Acknowledgements}

Scientific work was financed in the framework of project funded by the National Science Centre based on the decision number DEC-2012/05/B/ST8/00149. This publication was co-financed by the Ministry of Science and Higher Education of Poland as the statutory financial grant of the Faculty of Mechanical Engineering SUT.

\section{REFERENCES}

[1] O. Kwon, K. Lee, G. Kim, K. Chin, Mater Sci Forum. 638642, 136-141 (2010).

[2] W. Bleck, P. Larour, A. Baumer, Mater Forum 29, 21-28 (2005).

[3] International Iron \& Steel Institute Committee on Automotive Applications: Advanced High Strength Steel (AHSS) application guidelines, 2005, 69-74, www.ulsab.com (2012).

[4] C. Scott, S. Allain, M. Faral, N. Guelton, Rev Metall. 103, (6), 293-302 (2006).

[5] G. Frommeyer, U. Brüx, P. Neumann, ISIJ Int. 43, 438-446 (2003).

[6] O. Grässel, L. Krüger, G. Frommeyer, L.W. Meyer, Int J Plasticity 16, 1391-1409 (2000).

[7] U. Brüx, G. Frommeyer, O. Grässel, L.W. Meyer, A. Weise, Steel Res. 73, 294-298 (2002).

[8] L.A. Dobrzański, A. Grajcar, W. Borek, Mater Sci Forum. 638642, 3224-3229 (2010).

[9] L.A. Dobrzański, W. Borek, Mater Sci Forum. 654-656, 266269 (2010)

[10] L.A. Dobrzański, W. Borek, Mater Sci Forum. 706-709, 2053 2058 (2012).

[11] T. Tański, K. Labisz, B. Krupińska, M. Krupiński, M. Król, R. Maniara, W. Borek, J Therm Anal Calorim. (2015), DOI 10.1007/s10973-015-4871-y 123, (1), 63-74 (2016).

[12] A. Grajcar, R. Kuziak, Adv Mat Res. 314-316, 119-122 (2011).

[13] A. Grajcar, K. Radwanski, H. Krzton, Sol St Phen. 203-204, 34-37 (2013)

[14] The Future of Manufacturing in Europe 2015-2020, The Challenge for Sustainability, Materials, Final Report,
Groupe CM International, 2003, http://ec.europa.eu/research/ industrial_technologies/pdf/pro-futman-doc3a.pdf, (2013).

[15] F. Brandes, A. Lejour, G. Verweij, F. van der Zee, The Future of Manufacturing in Europe, Final Report, 2007, http://ec.europa. eu, (2013).

[16] A. Zieliński, G. Golański, M. Sroka, T. Tański, Mater High Temp. (2015), DOI: 10.1179/1878641315Y.0000000015 (in press).

[17] A.Zieliński,G.Golański,M.Sroka,J.Dobrzański,MaterSciTechLond. (2015), DOI: 10.1179/1743284715Y.0000000137 (in press).

[18] A. Zieliński, G. Golański, M. Sroka, Kovove Mater. 54, (1), 51-58 (2016)

[19] L.A. Dobrzański, W. Sitek, M. Krupiński, J. Dobrzański, J Mater Process Tech. 157, 102-106 (2004).

[20] M. Krupiński, L.A. Dobrzanski, J.H. Sokolowski, W. Kasprzak, G. Byczynski, Mater Sci Forum. 539-543, 339-344 (2007).

[21] T. Tański, P. Snopiński, W. Pakieła, W. Borek, K. Prusik, S. Rusz, Arch Civ Mech Eng. 16, (3), 325-334 (2016).

[22] A. Niechajowicz, A. Tobota, Arch Civ Mech Eng. 8, (2), 129137 (2008)

[23] L.A. Dobrzański, D. Pakuła, J. Mikuła, K. Gołombek, Int. J. Surface Science and Engineering 1, (1), 111-124 (2007).

[24] L. Da-Zhao, W. Ying-Hui, L. Chun-yue, H. Li-Feng, L. DongIeng, J. Xian-Zhe, J Iron Steel Res Int. 17, (6), 67-73 (2010).

[25] A. Zieliński, M. Miczka, B. Boryczko, M. Sroka, Arch. Civ. Mech. Eng. 2016, DOI:10.1016/j.acme.2016.04.010 (in press).

[26] A. Niechajowicz, A. Tobota, Arch Metall Mater. 54, (3), 647657 (2009).

[27] L.A. Dobrzański, M. Czaja, W. Borek, K. Labisz, T. Tanski, Int J Mater Prod Tec. 51, (3), 264-280, (2015).

[28] W. Sitek, Trans Famena, 34, (3), 39-46 (2010).

[29] W. Sitek, J. Trzaska, L.A. Dobrzański, Mater Sci Forum. 575578, (1-2), 892-897 (2008).

[30] L.A. Dobrzański, R. Maniara, J. Sokolowski W. Kasprzak, M. Krupiński, Z. Brytan, J Mater Process Tech. 192, 582-587 (2007).

[31] Z. Brytan, J. Niagaj, Chiang Mai J Sci. 40, (5), 923-937 (2013).

[32] L.A. Dobrzański, M. Bonek, M. Piec, E. Jonda, Mater Sci Forum. 532-533, 657-660 (2006). 